\title{
The role of apical-basal polarity in oral cancer
}

\author{
Saintigny $P^{1,2}$, Bouaoud $\mathrm{J}^{1,2}$, Farrugia $\mathrm{G}^{3}$ and Darido $\mathrm{C}^{3,4 *}$ \\ ${ }^{1}$ Univ Lyon, Université Claude Bernard Lyon 1, INSERM 1052, CNRS 5286, Centre Léon Bérard, Centre de recherche en cancérologie de Lyon, Lyon 69008, \\ France \\ ${ }^{2}$ Department of Medical Oncology, Centre Léon Bérard, Lyon, France \\ ${ }^{3}$ Division of Cancer Research, Peter MacCallum Cancer Centre, Grattan Street, Melbourne, Victoria 3000, Australia \\ ${ }^{4}$ Sir Peter MacCallum Department of Oncology, The University of Melbourne, Parkville, Victoria 3052, Australia
}

\begin{abstract}
Over the last thirty years, improvements in survival rates of oral cancer patients have remained modest, hampered by the late diagnosis of the disease, a lack of understanding of the underlying biology of oral cancer, and a lack of identified actionable targets. While the apical-basal polarity has been widely investigated in normal and pathological contexts, its involvement in oral homeostasis is still not well understood. Here, we discuss the current documented role of PAR-3 complexdependent apical-basal polarity regulation in oral cancer. We explore molecular switches that link polarity dysfunction to oral cancer initiation and highlight relevant models that would promote our understanding of disease development for therapeutic interventions.
\end{abstract}

\section{Introduction}

\section{Oral squamous cell carcinoma}

Head and neck squamous cell carcinoma (HNSCC) is the 6th most prevalent cancer worldwide, with more than half a million new cases reported annually [1,2]. Anatomical regions of SCC include the sinonasal and oral cavity, oropharynx, larynx, ear canal and trachea, with oral SCC (OSCC) being the most common malignancy of the head and neck region [3]. Patients diagnosed with OSCC have a particularly low five-year survival rate due to the compounding consequences of late detection [4,5]. Most OSCC patients usually present with advanced stage disease, and treatment is met with high levels of recurrence and metastasis [6,7]. In addition, OSCC patients continue to be at high risk of developing a second primary malignancy after their initial diagnosis $[8,9]$. The major risk factors for OSCC are tobacco use, alcohol abuse, betel nut chewing, genetic predisposition (eg. Fanconi anemia) and in the oropharyngeal anatomical subsite, infection with high-risk human papilloma viruses (HPV) [3,10]. Based on these differing aetiologies, it is hardly surprising at a molecular level that OSCC is a highly heterogeneous disease [11-14].

HPV-related oropharyngeal SCC are still diagnosed at lesser rates than HPV-negative OSCC and the prevalence of high-risk HPV positivity in OSCC varies widely between developing countries [1]. In the HPV-negative subsets, chronic exposures to carcinogens and extensive consumption of alcohol have been largely associated with the induction of neoplasms [1,15-17]. Oral leukoplakia and oral lichen planus are among the most frequent oral potentially malignant lesions and patients with those lesions are more susceptible to developing OSCC [18-21]. Comparably, immunosuppressed transplanted individuals are also prone to OSCC [22] and a high occurrence of oral cancer has been noted following post haematopoietic stem cell transplantation and liver transplant patients [23,24]. Despite those correlative studies, significant insights into the molecular mechanisms that initiate OSCC are still lacking. Therefore, defining the key effectors in oral homeostasis is an urgent clinical need with potentials to openup novel avenues for early detection of precancerous lesions, providing a scaffold for the development of survival improving preventative and therapeutic interventions against OSCC.

\section{Oral homeostasis}

The oral mucosa of the tongue consists of a connective tissue known as the lamina propria covered by squamous stratified cells forming the oral epithelium (OE). Stem and progenitor cells in the basal layer of the OE divide to repair any transient damage and to maintain rapid self-renewal of the tissue $[25,26]$. Upon commitment to differentiation, similar to skin keratinocytes, the proliferating cells polarize and migrate upward to form consecutively, the spinous, granular, clear and cornified layers $[27,28]$. The last step of this differentiation program establishes the cornified layer that provides a functional protective outer barrier in the dorsal tongue. In addition, terminally differentiated cells produce anti-microbial peptides that contribute to the protective response against any epithelial damage $[29,30]$.

Mutations in genes that regulate squamous differentiation were observed with high rates in oral cancers [12,13,31]. This suggests that oral homeostasis is tightly controlled by regulatory mechanisms of differentiation implicating dysregulation of this process as a driver of OSCC. It is well recognized that regulation of polarized protein segregation governs cell division, migration and differentiation, while

${ }^{\star}$ Correspondence to: Charbel Darido, Division of Cancer Research, Peter MacCallum Cancer Centre, Grattan Street, Melbourne, Victoria 3000, Australia; Sir Peter MacCallum Department of Oncology, The University of Melbourne, Parkville, Victoria 3052, Australia, Tel: +613 8559 7111, E-mail: charbel.darido@petermac.org

Key words: Par-3, polarity, FRMD4A, YAP, OSCC

Received: February 28, 2019; Accepted: March 08, 2019; Published: April 01, 2019 
disruption in these processes results in barrier function impairment, epithelial hyperproliferation and in some cases, SCC [32-35]. Important modulators of those mechanisms are apical-basal polarity complexes that have been shown to modulate keratinocyte differentiation and epithelial barrier function [36,37]. Therefore, the regulation of polarity proteins is essential for the normal function of stratified epithelia and for the maintenance of their homeostasis.

\section{Apical-basal polarity in oral cancer}

Different polarity complexes mark front, rear, apical, basal and adjacent sides of the cell allowing basal cells to self-replenish and remain in the basal layer while progenitor cells migrate towards the surface of the stratified epithelium. The Par-3/Par-6/aPKC/Cdc42 is an important polarity complex that contributes to those highly regulated processes by initiating the conversion of adherens junctions (AJ) to form "belt-like" junctions in preparation of epithelial cell polarization [38]. Gödde et al., has detailed the role of the Par-3 complex in polarity and cancer in multiple murine models showing that loss of PAR- 3 alone is not sufficient to induce malignant transformation, but rather requires additional oncogenic events [39]. In mammary tissues, ductal hyperplasia of Par-3- deficient cells did not progress to malignancy [40]. However, in various breast cancer mouse models, it was only following the induction of oncogenic hits that the tissues transformed to cancer, albeit at a faster progression rate in the absence of PAR-3 $[41,42]$. Furthermore, with regards to squamous epithelia, the polarity protein PAR-3 was shown to control epidermal homeostasis through regulation of barrier function, keratinocyte differentiation, and stem cell maintenance [43].

Nevertheless, and despite its established function in the skin, little is known about the role of core components of the Par-3 complex in squamous tissue homeostasis. A genome-wide screen of 684 human cancer cell lines revealed homologous PAR-3 exon microdeletions occurring predominantly in SCC, including OSCC. In addition, the loss of tight junctions in lung SCC is observed at the expense of PAR-3 deletion or suppression while the upregulation of yes- associated protein (YAP1) and aPKC were noted in OSCC and HNSCC, respectively $[44,45]$.

Because the Par-3 complex is involved in the sequential stratification of the oral epithelium [46,47] and since OSCC are characterized by disrupted differentiation and stratification, it is reasonably predictable that oral cells may have lost their ability to recognize apical-basal polarity at the initial stage of transformation. Therefore, through analyses of multiple PAR-3 partners and regulators, mechanistic insights into the function of Par-3 polarity complex could be seen shedding light on OSCC initiation.

\section{FERM domain containing 4A (Frmd4a)}

The FERM family of ezrin, radixin and moesin has been identified as integral for communication and transportation between the cytoskeleton and the plasma membrane, and co-localize with the Par3/Par-6/aPKC/Cdc42 complex [48]. The FERM proteins facilitate the linking of transmembrane proteins such as CD44, CD43, I-CAM2 and I-CAM3 within the intercellular space [49-53]. Interestingly, of the eight currently identified FERM proteins [54] only FRMD4a has been shown to play a role in the regulation of apical-basal polarity [38], oncogenesis $[55,56]$ and interaction with tumor promoting factors in OSCC [57]. FRMD4a is known to regulate the apical-basal polarity by linking the Par-3 complex with the guanine nucleotide exchange factor of Arf6, cytohesin-1, which is necessary for Arf6 activation consequently maintaining epithelial polarization (Figure 1) [38]. While FRMD4a is mainly expressed in basal cells of the oral stratified squamous epithelium, its expression is found reduced with differentiation with no signal detected in differentiated and terminally differentiated layers of the normal tissue [38]. On the other hand, FRMD4a is recognized as a stem cell marker in normal oral cells, and knockdown of Frmd4a either in vitro or in xenografts correlates with E-cadherin downregulation and subsequent reduction in cell proliferation. Furthermore, in situ hybridization of Frmd4a in OSCC sections demonstrated increased expression that is no more limited to basal cells [54] and prominent mRNA and protein expression of this stem cell factor were found in all OSCC lines tested [58,59]. Goldie et al., also noted a direct correlation between increased FRMD4a expression and the risk of OSCC recurrence in two retrospective data analyses [54]. Moreover, Zheng et al., complemented these findings and reported that there is a significant correlation between the overexpression of FRMD4a and the rate of OSCC metastasis to lymph nodes [55]. More interestingly, increased nuclear localization of YAP was associated with nuclear FRMD4a expression in SCC cells suggesting that FRMD4a may influence the Hippo pathway, dysregulating growth control and oral homeostasis

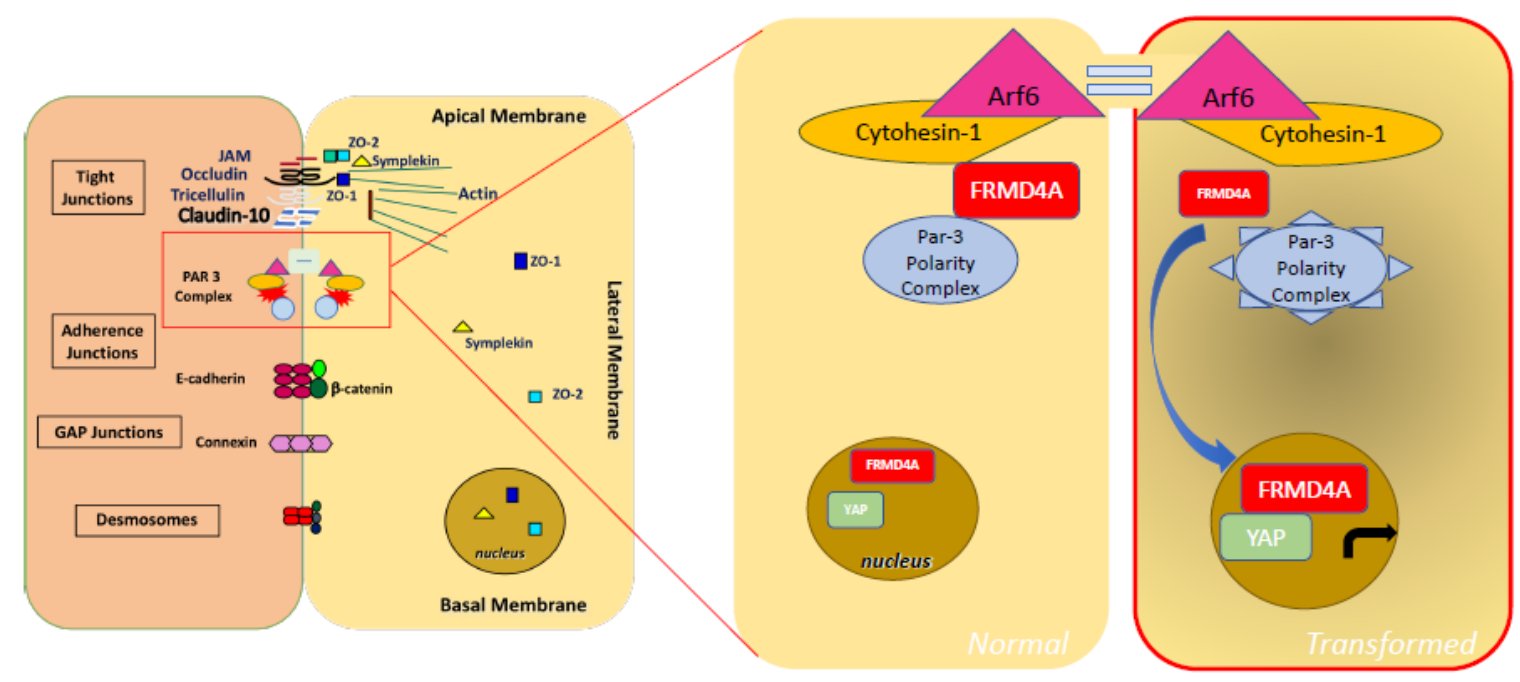

Figure 1. Schematic representation of FRMD4a interaction with the Par-3 polarity complex in the cytoplasm of normal cells and its association with YAP in the nucleus of transformed cells 
[54,59]. In earlier studies, FRMD4a was also shown to bind to YEATS domain containing 4 (aka YEATS4, Gas41), which is upregulated in tumor cells and predominantly expressed in the nucleoli [56]. Therefore, in a normal situation, cytoplasmic FRMD4a contributes through the Par-3 complex to apical-basal polarity, while the dissociation of FRMD4a and its relocalisation to the nucleus seems essential to initiate dysplastic transformations and to drive tumorigenesis (Figure 1). These data underline a merit to further explore the biological function of FRMD4a whereby future experiments could pioneer novel therapeutic approaches by either preventin 1g FRMD4a nuclear translocation or by targeting its downstream oncogenic function in oral cancer.

\section{Conclusion}

Our understanding of how the Par-3 apical-basal polarity complex influences oral differentiation, polarization, stratification and cancer development, whether through core components or binding partners, remains currently limited due to the lack of relevant laboratory and animal models. Future studies should be conducted to determine how FRMD4a interacts with PAR-3 in normal tissues and how FRMD4a dissociation and mis-localization to the nucleus could engage the HippoYAP signaling activation in the initiation of epithelial transformation, particularly in OSCC.

\section{Conflict of interest}

The authors declare no conflict of interest.

\section{Acknowledgments}

The authors are supported by grants from the Australian National Health and Medical Research (NHMRC, APP1049870, APP1106697), from The Association for International Cancer Research (AICR, 110060), by Fellowships from the Victorian Cancer Agency (Clare Oliver Memorial, COF11_04 and Mid-Career, MCRF15917) to CD and by the French LYriCAN grant (INCa-DGOS-Inserm_12563) to PS.

\section{References}

1. Marur S, Forastiere AA (2016) Head and neck squamous cell carcinoma: Update on epidemiology, diagnosis, and treatment. Mayo Clin Proc 91: 386-396. [Crossref]

2. Bray F, Ferlay J, Soerjomataram I, Siegel RL, Torre LA, et al. (2018) Global cancer statistics 2018: GLOBOCAN estimates of incidence and mortality worldwide for 36 cancers in 185 countries. CA Cancer J Clin, 68: 394-424.

3. Chi AC, Day TA, Neville BW (2015) Oral cavity and oropharyngeal squamous cell carcinoma--an update. CA Cancer J Clin 65: 401-421. [Crossref]

4. Gao W, Guo CB (2009) Factors related to delay in diagnosis of oral squamous cell carcinoma. J Oral Maxillofac Surg 67: 1015-1020. [Crossref]

5. Panzarella V, Pizzo G, Calvino F, Compilato D, Colella G, et al. (2014) Diagnostic delay in oral squamous cell carcinoma: the role of cognitive and psychological variables. Int J Oral Sci 6: 39-45. [Crossref]

6. Gonzalez-Garcia R, Naval-Gias L, Roman-Romero L, Sastre-Perez J, RodriguezCampo FJ (2009) Local recurrences and second primary tumors from squamous cell carcinoma of the oral cavity: a retrospective analytic study of 500 patients. Head Neck 31: $1168-80$.

7. Ribeiro IP, Caramelo F, Esteves L, Menoita J, Marques F, et al. (2017) Genomic predictive model for recurrence and metastasis development in head and neck squamous cell carcinoma patients. Sci Rep 7: 13897.

8. Baxi SS, Pinheiro LC, Patil SM, Pfister DG, Oeffinger KC, et al. (2014) Causes of death in long-term survivors of head and neck cancer. Cancer 120: 1507-1513. [Crossref]

9. Curtius K, Wright Na, Graham TA ( 2018) An evolutionary perspective on field cancerization. Nat Rev Cancer 18: 19-32.

10. Curado MP, Hashibe M (2009) Recent changes in the epidemiology of head and neck cancer. Curr Opin Oncol 21: 194-200. [Crossref]
11. Leemans CR, Braakhuis BJ, Brakenhoff RH (2011) The molecular biology of head and neck cancer. Nat Rev Cancer 11: 9-22. [Crossref]

12. Stransky N, Egloff AM, Tward AD, Kostic AD, Cibulskis K (2011) The mutational landscape of head and neck squamous cell carcinoma. Science 333, 1157-60.

13. Agrawal N, Frederick MJ, Pickering CR, Bettegowda C, Chang K, et al. (2011) Exome sequencing of head and neck squamous cell carcinoma reveals inactivating mutations in NOTCH1. Science 333: 1154-1157. [Crossref]

14. Foy JP, Bertolus C, Ortiz-Cuaran S, Albaret MA, Williams WN, et al. (2018) Immunological and classical subtypes of oral premalignant lesions. Oncoimmunology 7: e1496880.

15. Sanderson RJ, Ironside JA (2002) Squamous cell carcinomas of the head and neck BMJ 325: 822-827. [Crossref]

16. Abrigo M, Alvarez R, Paparella ML, Calb DE, Bal De Kier Joffe E, et al. (2014) Impairing squamous differentiation by Klf4 deletion is sufficient to initiate tongue carcinoma development upon K-Ras activation in mice. Carcinogenesis 35: 662-9.

17. Aldalwg MA, Brestovac B (2017) Human papillomavirus associated cancers of the head and neck: An Australian perspective. Head Neck Pathol 11: 377-384. [Crossref]

18. Waldron CA, Shafer WG (1975) Leukoplakia revisited. A clinicopathologic study 3256 oral leukoplakias. Cancer 36: 1386-1392.

19. Lo Muzio L, Mignogna Md, Favia G, Procaccini M, Testa NF, et al. (1998) The possible association between oral lichen planus and oral squamous cell carcinoma: a clinical evaluation on 14 cases and a review of the literature. Oral Oncology, 34: 239-246.

20. Ebrahimi M, Nylander K, van der Waal I (2011) Oral lichen planus and the p53 family: what do we know? J Oral Pathol Med 40: 281-285. [Crossref]

21. Foy JP, Bertolus C, Saintigny P (2019) Oral cancer prevention worldwide: Challenges and perspectives. Oral Oncol 88: 91-94. [Crossref]

22. Alsidawi S, Price KA, Chintakuntlawar AV, Westin GF, Garcia JJ (2017) Characteristics and long-term outcomes of head and neck squamous cell carcinoma after solid organ transplantation. Oral Oncology 72: 104-109.

23. Masserot C, Peffault De Latour R, Rocha V, Leblanc T, Rigolet A, et al. (2008) Head and neck squamous cell carcinoma in 13 patients with Fanconi anemia after hematopoietic stem cell transplantation. Cancer 113: 3315-3322.

24. Coordes A, Albers AE, Lenarz M, Seehofer D, Puhl G, et al. (2016) Incidence and long-term survival of patients with de novo head and neck carcinoma after liver transplantation. Head Neck 38: 707-714. [Crossref]

25. Darido C, Jane SM (2010) Grhl3 and GEF19 in the front rho. Small GTPases 1: 104 107. [Crossref]

26. Darido C, Jane SM (2013) Golgi feels its own wound. Adv Wound Care 2: 87-92. [Crossref]

27. Cangkrama M, Ting SB, Darido C (2013) Stem cells behind the barrier. Int J Mol Sci 14: 13670-13686. [Crossref]

28. Youssef M, Cuddihy A, Darido C (2017) Long-Lived epidermal cancer-initiating cells. Int J Mol Sci 18. [Crossref]

29. Darido C, Georgy SR, Wilanowski T, Dworkin S, Auden A, et al. (2011) Targeting of the tumor suppressor GRHL3 by a miR-21-dependent proto-oncogenic network results in PTEN loss and tumorigenesis. Cancer Cell 20: 635-648.

30. Darido C, Georgy SR, Jane SM (2016) The role of barrier genes in epidermal malignancy. Oncogene 35: 5705-5712. [Crossref]

31. Georgy SR, Cangkrama M, Srivastava S, Partridge D, Auden A, et al. (2015) Identification of a novel proto-oncogenic network in head and neck squamous cell carcinoma. J Natl Cancer Inst 107. [Crossref]

32. Mlacki M, Darido C, Jane SM, Wilanowski T (2014) Loss of grainy head-like 1 is associated with disruption of the epidermal barrier and squamous cell carcinoma of the skin. PLoS One 9: e89247. [Crossref]

33. Darido C, Georgy SR, Cullinane C, Partridge DD (2018) Stage-dependent therapeutic efficacy in PI3K/mTOR- driven squamous cell carcinoma of the skin. Cell Death Differ 25: 1146-1159.

34. Goldie SJ, Cottle DL, Tan FH, Roslan S, Srivastava S, et al. (2018) Loss of GRHL3 leads to TARC/CCL17-mediated keratinocyte proliferation in the epidermis. Cell Death Dis 9: 1072.

35. Dworkin S, Jane SM, Darido C (2011) The planar cell polarity pathway in vertebrate epidermal development, homeostasis and repair. Organogenesis 7: 202-8. 
36. Niessen MT, Iden S, Niessen CM (2012) The in vivo function of mammalian cell and tissue polarity regulators--how to shape and maintain the epidermal barrier. $J$ Cell SCi 125: 3501-3510. [Crossref]

37. Ikenouchi J, Umeda M (2010) FRMD4A regulates epithelial polarity by connecting Arf6 activation with the PAR complex. Proc Natl Acad Sci U S A 107: 748-753. [Crossref]

38. Gödde NJ, Pearson HB, Smith LK, Humbert PO (2014) Dissecting the role of polarity regulators in cancer through the use of mouse models. Exp Cell Res 328: 249-257. [Crossref]

39. Mccaffrey LM, Macara IG (2009) The Par3/aPKC interaction is essential for end bud re modelling and progenitor differentiation during mammary gland morphogenesis. Genes \& development 23: 1450-1460.

40. Xue B, Krishnamurthy K, Allred DC, Muthuswamy SK (2013) Loss of Par3 promotes breast cancer metastasis by compromising cell-cell cohesion. Nat Cell Biol 15: 189200. [Crossref]

41. Mccaffrey, Luke M, Montalbano J, Mihai C, Macara Ian G (2012) Loss of the Par3 polarity protein promotes breast tumorigenesis and metastasis. Cancer Cell 22: 601 614

42. Ali NJ, Dias Gomes M, Bauer R, Brodesser S, Niemann C, et al. (2016) Essential role of polarity protein par3 for epidermal homeostasis through regulation of barrier function, keratinocyte differentiation, and stem cell maintenance. $J$ Invest Dermatol 136: $2406-2416$

43. Rothenberg SM, Mohapatra G, Rivera MN, Winokur D, Greninger P, et al. (2010) A genome-wide screen for microdeletions reveals disruption of polarity complex genes in diverse human cancers. Cancer Res 70: 2158-64.

44. Martin-Belmonte F, Perez-Moreno M (2011) Epithelial cell polarity, stem cells and cancer. Nat Rev Cancer 12: 23-38. [Crossref]

45. Lin D, Edwards AS, Fawcett JP, Mbamalu G, Scott JD, et al. (2000) A mammalian PAR-3-PAR-6 complex implicated in Cdc42/Rac1 and aPKC signalling and cell polarity. Nat Cell Biol 2: 540-547. [Crossref]

46. Joberty G, Petersen C, Gao L, Macara IG (2000) The cell-polarity protein Par6 links Par3 and atypical protein kinase C to Cdc42. Nat Cell Biol 2: 531-539. [Crossref]

47. Chishti AH, Kim AC, Marfatia SM, Lutchman M, Hanspal M, et al. (1998) The FERM domain: a unique module involved in the linkage of cytoplasmic proteins to the membrane. Trends in Biochemical Sciences 23: 281-282.
48. Arpin M, Algrain M, Louvard, D (1994) Membrane-actin microfilament connections: an increasing diversity of players related to band 4.1. Current Opinion in Cell Biology 6: 136-141

49. Sachiko T, Kumiko O, Naruki S, Junji S, Akihiko K, et al. (1994) ERM family member as molecular linkers between the cell surface glycoprotein CD44 and actin-based cytoskeletons. The Journal of Cell Biology 126: 391-401.

50. Bretscher A, Reczek D, Berryman M (1997) Ezrin: a protein requiring conformationa activation to link microfilaments to the plasma membrane in the assembly of cell surface structures. J. Cell Sci 110: 3011-3018.

51. Serrador JM, Alonso-Lebrero JL, Pozo MAD, Furthmayr H, Schwartz-Albiez R, et al. (1997) Moesin Interacts with the cytoplasmic region of intercellular adhesion molecule-3 and is redistributed to the Uropod of T lymphocytes during cell polarization. The Journal of Cell Biology 138: 1409-1423.

52. Yonemura S, Hirao M, Doi Y, Takahashi N, Kondo T, et al. (1998) Ezrin/Radixin Moesin (ERM) proteins bind to a positively charged amino acid cluster in the juxtamembrane cytoplasmic domain of CD44, CD43, and ICAM-2. The Journal of Cell Biology 140: 885-895.

53. Moleirinho S, Tilston-Lunel A, Angus L, Gunn-Moore F, Reynolds PA (2013) The expanding family of FERM proteins. Biochem J 452: 183-193. [Crossref]

54. Goldie SJ, Mulder KW, Tan DW, Lyons SK, Sims AH, et al. (2012) FRMD4A upregulation in human squamous cell carcinoma promotes tumor growth and metastasis and is associated with poor prognosis. Cancer Res 72: 3424-36.

55. Zheng X, Jia B, Lin X, Han J, Qiu X, et al. (2016) FRMD4A: A potential therapeutic target for the treatment of tongue squamous cell carcinoma. Int J Mol Med 38: 1443 1449 .

56. Piccinni E, Chelstowska A, Hanus J, Widlak P, Loreti S (2011) Direct interaction of Gas41 and Myc encoded by amplified genes in nervous system tumours. Acta Biochim Pol 58: 529-534. [Crossref]

57. Jensen KB, Watt FM (2006) Single-Cell expression profiling of human epidermal stem and transit-amplifying cells: lrig1 is a regulator of stem cell quiescence. Proceeding. of the national academy of sciences of the united states of America 103: 11958-11963.

58. Jensen KB, Jones J, Watt FM (2008) A stem cell gene expression profile of human squamous cell carcinomas. Cancer Letters 272: 23-31.

59. Halder G, Dupont S, Piccolo S (2012) Transduction of mechanical and cytoskeleta cues by YAP and TAZ. Nat Rev Mol Cell Biol 13: 591-600. [Crossref]

Copyright: $\mathbb{C} 2019$ Saintigny P. This is an open-access article distributed under the terms of the Creative Commons Attribution License, which permits unrestricted use, distribution, and reproduction in any medium, provided the original author and source are credited. 